\title{
Analysing Technological Affordances of Online Interactions Using Conversation
}

\section{Analysis}

\begin{abstract}
The use of conversation analysis (CA) as a method for analysing the interactional practices of online communication has been growing in recent years (Giles, Stommel, Paulus, Lester \& Reed, 2015). A key challenge for analysing online communication is the varied platforms through which interaction can occur. This paper demonstrates how using CA and the concept of affordances (Hutchby, 2001) can provide a lens through which to analyse not only the interaction, but also the technological context of that interaction. A corpus of instant messaging chats, captured from Facebook chat using screen-capture software, is used as a case study to demonstrate how the concept of affordances can be used alongside CA analysis to address the role of technology in the interaction. Two key interactional practices - turn adjacency and openings - are analysed to show the insights that CA can offer for providing an in-depth analysis of online interaction. By using affordances as a lens through which CA analysis can be refracted, scholars using 'digital CA' can better develop an understanding of patterns of interaction across different interactional platforms.
\end{abstract}

Keywords: Conversation analysis; technological affordances; instant messaging; online interaction; screen-capture 


\section{CONVERSATION ANALYSIS AND TECHNOLOGICAL AFFORDANCES}

\section{Introduction}

The study of online interaction using conversation analysis (CA) has grown in recent years (Giles, Stommel, Paulus Lester, \& Reed, 2015). This 'digital' CA does not focus just on the topic of online interaction, but also addresses the interactional norms, dynamics and practices which have arisen online (Giles et al., 2015). Studies of online interaction which use CA have been categorized according to their main aims (Paulus, Warren \& Lester, 2016). The first type of study tends to compare face-to-face interaction with online talk (e.g., Author, 2014; Garcia \& Jacobs, 1999). In other words, this research analyses online interaction and compares it with findings from studies of spoken interaction. The second category of research aims to understand how online talk is coherent to participants, most prominently focusing on disrupted turn adjacency (e.g., Berglund, 2009). A third type of research aims to understand how participants deal with trouble in talk; in other words, it focuses on repair (e.g., Schönfeldt \& Golato, 2003; Author \& \{anonymised\}, 2014). The final category of research focuses on how participants accomplish social actions in asynchronous environments (e.g., Paulus \& Lester, 2013; Stommel \& Koole 2010). Paulus et al. (2016) note that articles which fall into this latter category often use discursive psychology, but draw upon CA in order to understand broader social practices in online interaction.

Despite this growing literature which uses digital CA, the field is still in its infancy when compared to spoken CA, and there are still methodological questions to be addressed. One question relates to the extent to which spoken CA findings should be used in the analysis of online interaction (Greiffenghane \& Watson., 2005). For example, there is an issue in online interaction with presuming, as CA does, that communication is linear, whereas in online communication there are often issues with sequential disruption (Herring, 1999). A second question is how to take account of the technological context. In spoken CA the interactional context should be demonstrably relevant to the participants themselves (Sidnell, 


\section{CONVERSATION ANALYSIS AND TECHNOLOGICAL AFFORDANCES}

2010). This means that the analyst should be able to demonstrate that the fact that the talk is conducted in a particular setting has consequences "for the shape, form, trajectory, content, or character of the interaction" (Schegloff, 1991, p.53). For digital CA we can re-purpose this argument to suggest it is necessary to demonstrate that the fact that the interaction occurs on a particular technological platform has consequences for the shape, form, trajectory or character of the interaction.

In order to examine the role of technology in interaction, the concept of 'affordances' can be drawn upon. This concept was first developed by Gibson (1979) within the field of psychology of perception. For Gibson, an affordance refers to the possibilities that any object offers for action. This does not mean that an object does not have particular properties; however, these properties only emerge through interaction between actors and those objects. The way in which an actor interacts with an object is not, though, only related to its physical properties but also to social norms and rules (Gibson, 1979). Norman (1988) further developed this notion of affordances in relation to human-computer interaction. Norman similarly noted that an affordance should not be understood as a property, but rather as a relationship. He argues that an affordance is not a static feature of an object, but rather whether an affordance exists depends entirely upon the relationship between the actor and the property. The concept of affordances, therefore, allows for the possibility that the practices of online interaction are not determined by the technology, but rather by how an actor uses that technology. Affordances are not, then static features of technology, but are features that can be seen by users as having a number of potential actions associated with them. Therefore, an affordance exists once a user has perceived it and perceived the potential actions associated with it.

Hutchby (2001) drew on the concept of affordances when analysing technologized interaction using CA. As both Gibson and Norman did, Hutchby argued that features of 


\section{CONVERSATION ANALYSIS AND TECHNOLOGICAL AFFORDANCES}

technology can both afford and constrain the interactional potential (Hutchby, 2001), but that using the concept of affordances allowed us to move away from both technological determinism and social constructionism in the analysis of technologized interaction. Therefore, the concept of affordances allows for an analysis of online interaction, which also demonstrates how the interaction orients to particular technological features. The concept of affordances has been used alongside CA in analysing interaction of multi-party chat rooms (Hutchby, 2001), mobile telephones (Hutchby \& Barnett, 2005), text messaging (Hutchby \& Tanna, 2008) and video messaging (Rintel, 2013). There have been limited studies which have discussed the affordances of one-to-one private instant messaging. However, a recent study by Stommel and te Molder (2016) considered the notion of affordances in relation to one-to-one online counselling sessions. They noted that the affordances of an interaction - in their case a pre-screening questionnaire - may in fact hinder the interaction, due to the interactional norms which may become relevant to the interaction. In other words, they highlighted a potentially unexpected relationship between the technology and how the interaction unfolded.

In this article, I demonstrate an analysis of instant messaging interaction using CA and viewed through the lens of affordances. I aim to show how this method of analysis allows for an in-depth understanding of the technological and interactional context of instant messaging interaction. how by using CA it is possible to explore the interactional context, and affordances can be used as a lens through which to view the technological context.

\section{Methods}

\section{Data collection}

The data in this article comes from interactions conducted via Facebook chat, the instant messaging service on the social networking site Facebook. The data were collected in 2011- 


\section{CONVERSATION ANALYSIS AND TECHNOLOGICAL AFFORDANCES}

2012, when Facebook chat could only be used for instant messaging rather than as private messaging. At the time of data collection, the chat facility on Facebook appeared at the bottom of a user's profile page and allowed them to talk to their friends 'in real time' The chats collected are one-to-one interactions, where both participants have to be online at the same time in order to interact, with each user typing their message in the "message construction' box (see Figure 1). The person to whom they are chatting cannot see what is being written here. However, if the co-participant is writing, a small writing icon will appear next to their name as in Figure 1. Once a message is sent it appears in the chat window and is visible to both participants.

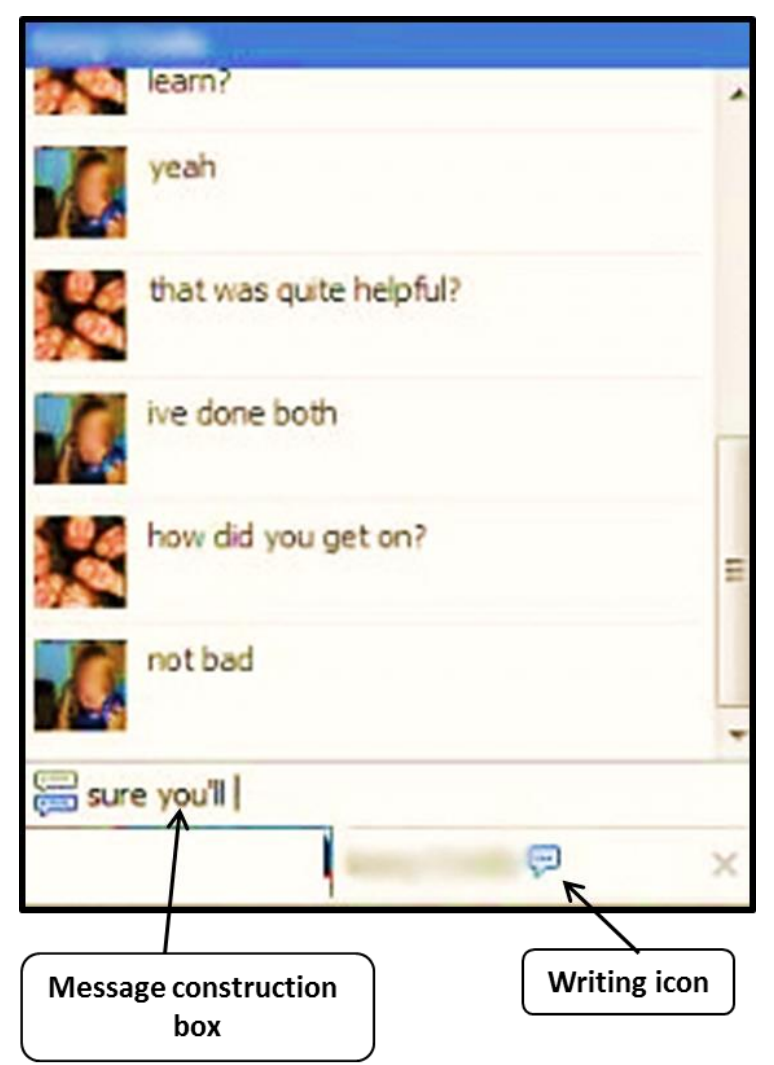

Figure 1. Facebook chat window showing message construction and writing icon.

\section{Participants}

Four participants were recruited through advertising to students in lectures at the author's 


\section{CONVERSATION ANALYSIS AND TECHNOLOGICAL AFFORDANCES}

university. These participants all collected chat logs of their Facebook chats. In addition, screen-capture software was used by participants to record their screens while they were conducting their chats. This method for collecting data for a conversation analytic study is relatively rarely used, but allows the analyst to have access to the real-time unfolding of the interaction. Once the participants had recorded their chats they returned the screen-capture and $\log$ files to the author on DVD. Informed consent was obtained from all participants, both those collecting data and the people they were interacting with on Facebook chat. 75 Facebook chats, totalling 37 hours 55 minutes, were collected from the four main participants, with 33 different chat partners. All data were anonymized, removing any identifying details, with pseudonyms used for participants.

\section{Data transcription}

A transcription system was developed for the screen-capture data, which was based on the Jefferson system (Author, 2015). The following extract provides a brief example of some of the key transcription symbols used in this paper.

Extract 1: JM/IS6/F/48-51

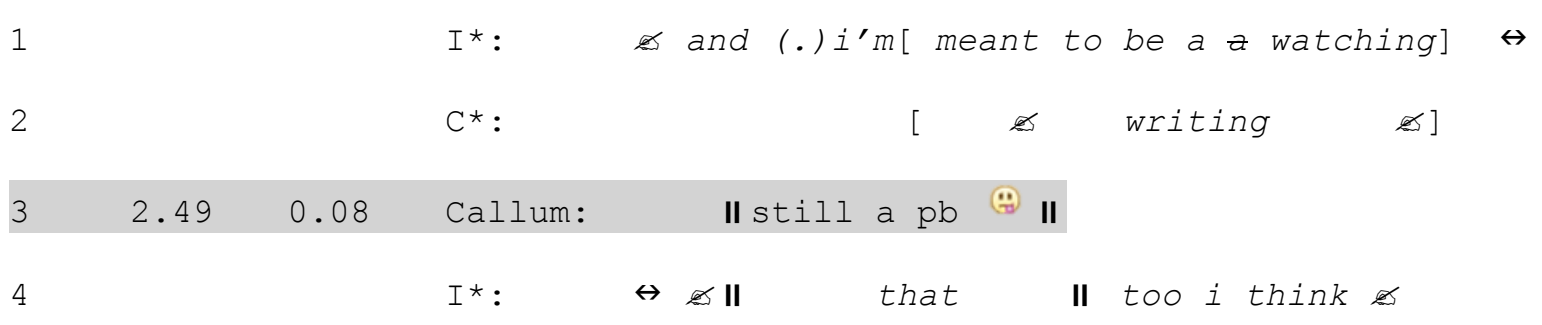

The transcript is laid out in a column format, with the first column used for line numbers; the second column is the cumulative time of the chat; the third column indicates the time between turns; the fourth column is the name of the participant; and column 5 is the actual interaction. Lines in the chat which both participants have access to are highlighted in grey 


\section{CONVERSATION ANALYSIS AND TECHNOLOGICAL AFFORDANCES}

and the participant's full name is used in column 4 (line 3). If the line refers to some action taken from the screen-capture video, then only the initial of the participant is used.

In the final column, symbols are used to denote certain actions. The symbol at the beginning of line 1 is used to indicate that the participant is constructing a message and this is not available to the co-participant. Square brackets are used to denote overlap (lines 1 and 2). In the overlapping section, the actual text that the participant in line 1 (Isla) is writing is available because she is recording her screen. However, the text that Callum is writing in line 2 is not available (either to me as an analyst or to Isla), but it is possible to know that he is writing due to the writing icon in the chat window. As Callum posts his completed message in line 3, Isla's message construction does not stop, but rather is presented over two lines of the transcript. This is indicated by a double-headed arrow $(\leftrightarrow)$ placed at the end of line 1 and at the beginning of line 4 to show 'latching'. Callum posts his turn "still a pb" with the II II symbols used to denote that Callum's entire turn appeared at the same time as Isla wrote the word "that" (line 4). A full list of transcription symbols is available in the appendix.

\section{Data analysis}

Once the data had been transcribed, they were analysed using CA (Sacks, 1992), and specifically digital CA (Giles et al., 2015). CA conceptualizes interaction as "a social institution in its own right" (Heritage, 1995, p. 393), which can be examined in close empirical detail in order to find the normative practices of interaction (Potter, 2012). For this study, both the chat logs and the screen capture data were examined in detail, and interesting interactional features of the participants' conduct was noted. Once the analysis of the interaction had been conducted, it was then examined to see if, and how, their interactional practices oriented to any particular affordance. 


\section{Results}

The analysis presented here will show how examining online interaction through the lens of affordances can provide insight into the interactional and technological context of Facebook chat. For each extract, the interaction will be analysed, before the relationship between the interaction and the technology is discussed. The analysis aims to show how using CA alongside the concept of affordances can allow us to illuminate the ways in which technology and interaction intersect. The first section will examine an interactional practice which is commonly noted in the literature on online interaction; that is, disrupted turn adjacency. The second section will examine Facebook chat openings.

\section{Turn adjacency}

In spoken interaction, adjacency pairs have been identified as the basic building blocks of sequences of interaction (Schegloff \& Sacks, 1973). They are composed of two turns, produced by different speakers and are adjacent to one another in the conversation. It is through the next turn that a speaker demonstrates their understanding of the prior turn, and so when this 'nextness' or adjacency is disrupted in online interaction, it could potentially lead to miscommunication. The issue of disrupted turn adjacency is often raised in relation to online interaction, and refers to the difficulty of identifying which utterances 'belong' together (Herring, 1999). Disrupted turn adjacency is often attributed to co-participant not having access to the content of a message-in-construction or knowing when it is likely to be sent; therefore, participants are unable to mutually co-ordinate turn-taking (Garcia \& Jacobs, 1999). The ways in which participants maintain coherence have been well-rehearsed in the literature (e.g., Berglund, 2009; Greenfield \& Subrahmanyam, 2003; Herring, 1999; Garcia \& Jacobs, 1999). However, previous studies have - for the most part - only had access to the 


\section{CONVERSATION ANALYSIS AND TECHNOLOGICAL AFFORDANCES}

$\log$ files (although see Garcia \& Jacobs, 1999). As noted above, the data presented here were recorded using screen-capture software, which enabled not only the analysis of the posted messages, but also the analysis of the interaction as it unfolded. The aim, therefore is not to show that disrupted turn adjacency occurs, but to show how it occurs, and what using the concept of affordances can add to the analysis.

The following extract, from a chat between Joe and Isla in which they discuss whether to meet up that evening, is an example of the production of disrupted turn adjacency in online chat.

Extract 2: JM/IS20/F/376-381

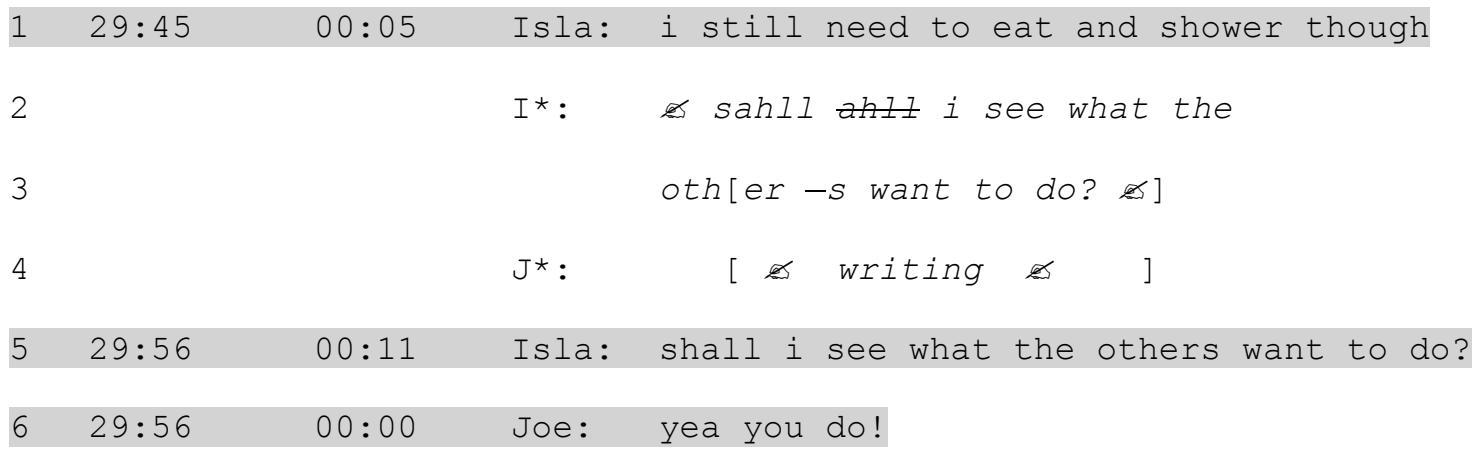

In line 1, Isla has posted an account for why she needs some time to get ready before going over to Joe's. After posting this message, she posts a new first pair part (FPP) of an adjacency pair at line 5 to check whether she should extend Joe's prior invitation to her other flatmates. At almost the exact time that Isla posts her FPP, Joe posts a response 'yea you do!'. Studies have suggested that participants are able to maintain coherence online through various means, including lexical repetition, conjunctions and so on (Berglund, 2009; Schönfeldt \& Golato, 2003), as well as ensuring that the SPP of an adjacency pair is clearly fitted to the FPP in terms of its action (Author, 2014). However, the content of line 6 could potentially be a response to either line 1 (telling Isla she needs to shower) or to line 5 (Joe effectively saying 


\section{CONVERSATION ANALYSIS AND TECHNOLOGICAL AFFORDANCES}

'yes, do that'). However, once we start to unpack what is happening based on the timings and the screen-capture, we can see that this turn has to be responsive to line 1 .

After Isla posts her turn in line 1, she then immediately starts to construct another message. This can be seen from the writing icon in line 2. Before she finishes her message construction, Joe also starts to write a message (line 4), which is also indicated by the writing icon. Both parties finish writing at about the same time, but Isla sends her message slightly before Joe, so her message appears first in the chat window.

The interaction is, then, a fairly simply question-answer adjacency pair, but there is a message which 'disrupts' this pair. By analysing this simple example we can also examine what affordances are relevant. Firstly, as with many other forms of text-based online interaction, messages are constructed and sent separately (Garcia \& Jacobs, 1999; Markman, 2009). In practice, this affordance is utilised by participants to write messages at the same time. There is a writing icon which informs participants if their interlocutor is currently writing a message. In Extract 2 Joe starts writing while Isla is already in the process of constructing her message (line 4). Joe could, having presumably seen the writing icon, waited for Isla to complete and send her message before starting his own. So although the technology affords Joe the possibility of avoiding overlapping writing with Isla, this is not how the interaction unfolds. It could possibly be argued that the writing icon provides participants who are writing at the same time with some indication that there may be some disrupted turn adjacency. It is important to note, though, that the interaction does not appear to be problematic for the participants and there is no miscommunication in terms of which turns relate to one another. The technology, therefore, affords a number of possible actions, including the possibility to write at the same time, but also offers the writing icon to potentially avoid this. However, the 'norms and social conventions' (Gibson, 1979) of instant messaging allow for participants to construct messages at the same, which can lead to 


\section{CONVERSATION ANALYSIS AND TECHNOLOGICAL AFFORDANCES}

disrupted turn adjacency.

The following extract demonstrates a further example of how disrupted turn adjacency may illuminate specific technological affordances. Joe and Isla are discussing what they have done, and are going to do, that day. Just prior to this extract, Joe has mentioned that he needs to shower and cook.

Extract 3: JM/IS20/F/102-117

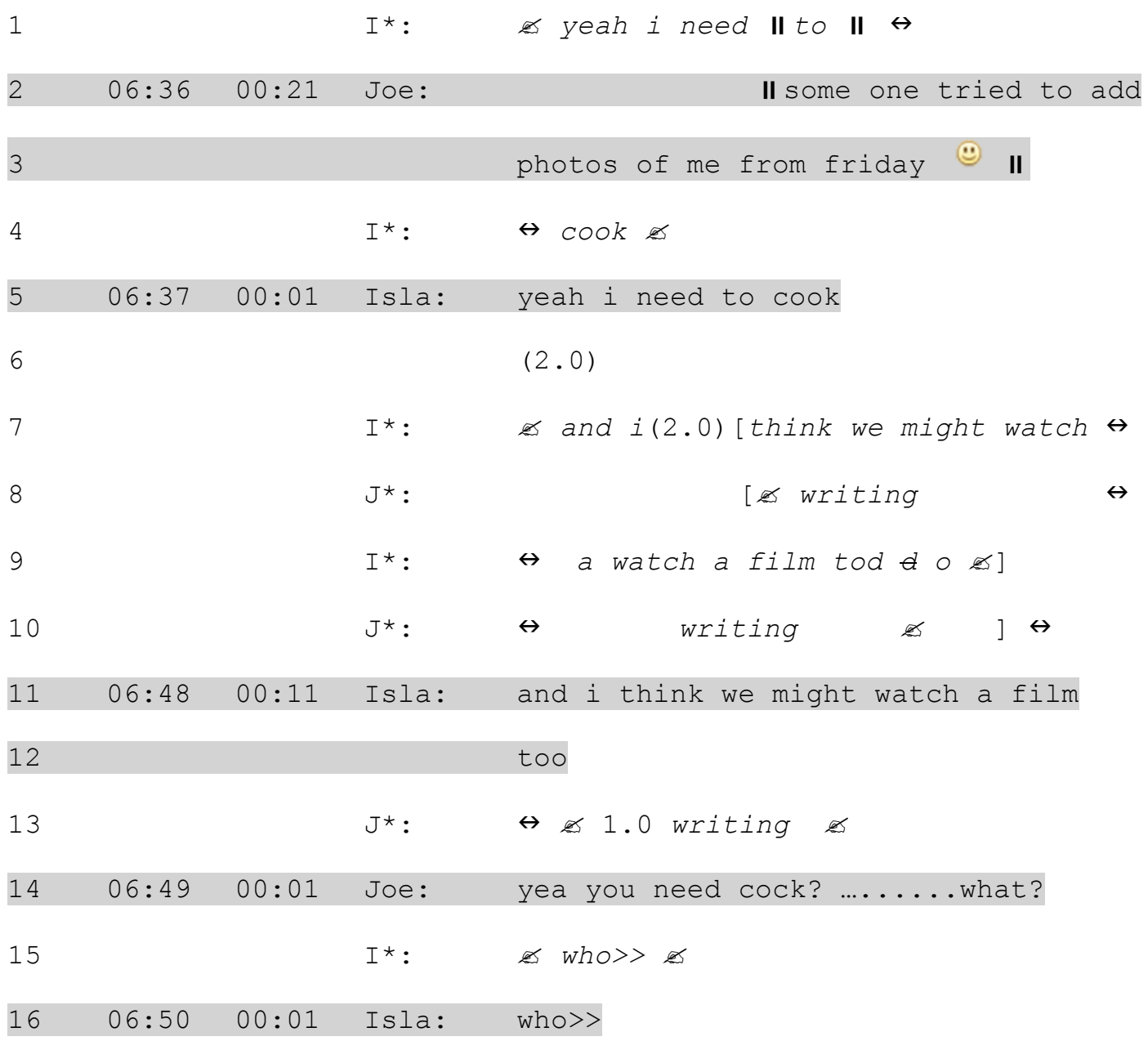

In the first turn, Joe posts a message which is the first part of a new adjacency pair, about someone adding photos of him (on Facebook). Isla's next message, though, is entirely unrelated to Joe's post, but instead is related to a prior turn. Isla's next turn is an example of 


\section{CONVERSATION ANALYSIS AND TECHNOLOGICAL AFFORDANCES}

what is sometimes called 'breaking up' turns (Benwell \& Stokoe, 2006; Tudini, 2015. It is difficult to provide clear evidence that this should necessarily be understood as one single turn. However, Isla does link her related turns together at lines 11-12 through the conjunction 'and', thus maintaining some coherence between her turns (Turk, 2004). Joe's response at line 14 is also dislocated from the related turn which, based on the lexical and grammatical repetition (Berglund, 2009), can be understood as a, presumably ironic, misreading of the word "cook" in line 5. So far, Joe's turn about the photos has not been responded to. In line 16, Isla asks "who" which makes relevant a person as a response (Lee, 2013), and so is semantically linked to Joe's turn at line 8-9. Therefore, Isla responds to Joe's turn after 3 unrelated messages have been sent.

When we examine what is happening on-screen as the interaction unfolds, we can see that in line 1 Isla is already constructing her message which appears in line 5 prior to Joe posting his turn at line 2-3. In line 7 Isla starts to construct another message, but around 3 seconds after she starts writing, Joe starts to write a message. Between lines 7 and 10 both parties are constructing messages simultaneously, with neither party having access to the other person's message-in-construction, so they cannot know when the other person will send their message. Isla sends her message to the chat window first, an upshot of which is that Joe's subsequent turn, which is sent around a second later, is dislocated from the related turn (line 5). So, even though there is a FPP of an adjacency pair which could be responded to (Joe's turn in lines 2-3), Isla instead chooses to add another turn about her plans for the day, rather than responding to the immediately prior turn.

As with the previous extract, here the technology affords the possibility that the participants could write messages at the same time, with a 'writing icon' appearing on-screen to indicate that this is happening. The writing icon provides a limited possibility to be able to co-ordinate turn-taking, by avoiding writing when this icon is on-screen. However, in this 


\section{CONVERSATION ANALYSIS AND TECHNOLOGICAL AFFORDANCES}

extract Isla and Joe do not appear to make use of this in this way, as they write at the same time.

It is notable that at line 11-12 Isla does not to respond to Joe's announcement about the photos on Facebook until after she has finished constructing another turn which is related to her own plans for the day. In other words, she chooses to 'break up' what could feasibly one longer message into a number of shorter turns, leading to disrupted turn adjacency. As has been noted by previous studies, the persistence of text on-screen means that participants "can scroll up or scroll down the record on the screen when they do not understand the conversational thread" (Greenfield \& Subrahmanyam, 2003, p.731). The persistence of text on-screen also affords this 'breaking up' of turns, as the recipient can deduce which turns 'fit' together through examining the record of the interaction as it appears on screen.

The following extract further demonstrates 'breaking up' of turns. Here, Isla and Callum have been engaged in an exchange of teases.

Extract 4: JM/IS5/F/360-374

\begin{tabular}{|c|c|c|c|c|}
\hline 1 & $23: 15$ & $00: 11$ & Callum: & im just joking with you paaaal \\
\hline 2 & & & $I *:$ & a 3.0 chatting to $\mathrm{MP} \boldsymbol{\sigma} \leftrightarrow$ \\
\hline 3 & $23: 18$ & $00: 03$ & Callum: & chillax \\
\hline 4 & & & $I *:$ & $\leftrightarrow \boldsymbol{a} 22.0$ chatting to $\mathrm{MP} \boldsymbol{\Omega} \leftrightarrow$ \\
\hline 5 & $23: 40$ & $00: 22$ & Callum: & do you have a formspRING? \\
\hline 6 & & & $I *:$ & a 12.0 chatting to $\mathrm{MP} \boldsymbol{0}$ \\
\hline 7 & & & & ((Switches to chat with William)) \\
\hline 8 & & & & a 11.0 chatting to William \\
\hline 9 & & & & ((Switches to chat with Callum)) \\
\hline 10 & & & & (10.0) i know you areeee \\
\hline 11 & $24: 16$ & $00: 36$ & Isla: & i know you areeee \\
\hline 12 & & & $I *:$ & \& you're just a joker.... \& \\
\hline
\end{tabular}


CONVERSATION ANALYSIS AND TECHNOLOGICAL AFFORDANCES

\begin{tabular}{|c|c|c|c|c|}
\hline 13 & $24: 20$ & $00: 04$ & Isla: & you're just a joker.... \\
\hline 14 & & & $I *:$ & \& ? ? and a what?! :-S \\
\hline 15 & $24: 25$ & $00: 05$ & Isla: & what?! :-S \\
\hline
\end{tabular}

Callum posts 3 turns in lines 1, 3 and 5, with the final turn (line 5) the first part of a questionanswer adjacency pair. When Isla responds to Callum's turns, she responds in the order in which they were posted. Thus, Isla's turns in lines 11 and 13 are responsive to Callum's turn in line 1 , which means that the response to the question about the 'Formspring' ('and a what?!') occurs in line 15 and so is dislocated from the FPP. As with the previous extract, the participants make use of the fact that the text remains on screen to send these multiple consecutive turns and to respond in a list-format. The practice of responding to messages in a list-format has been found in other written technologies, where text also remains on-screen, suggesting the importance of this affordance in terms of this practice (Hutchby \& Tanna, 2008; Nilsen \& Mäkitalo, 2010). Of course, the persistence of text on screen is merely the affordance which allows for this particular action to occur, it does not fully explain why it occurs. This breaking up of turns may also relate to the separation of message construction and sending; that is, as there can often be a long gap while a new message is being written, sending multiple shorter messages provides something for the recipient to read while a new message is being written (Benwell \& Stokoe, 2006). So, the fact that text remains on-screen affords the possibility for sending multiple turns, which in itself manages what could be seen as a potential constraint (or anti-affordance; Norman, 1988), that is, the separation of message construction and sending.

This section has demonstrated that, as previous studies have found, disrupted turn adjacency is at least partially an upshot of the separation of message construction and sending, which allows for participants to write messages at the same time. They are unable to co-ordinate turn-taking, which can lead to disrupted turn adjacency. However, Facebook chat 


\section{CONVERSATION ANALYSIS AND TECHNOLOGICAL AFFORDANCES}

provides the potential affordance of the writing icon, which could help participants to in some way co-ordinate turn-taking. In this section, though, it has been shown that the participants do not seem to make use of this icon to avoid writing at the same time. It may be that the writing icon simply signifies to participants that there may be some disrupted turn adjacency if they are writing at the same time, rather than being treated as a way of avoiding it. Another reason for disrupted turn adjacency occurring is that participants choose to send multiple turns and respond to them in list-format. In terms of affordances, we can see that the persistence of text on-screen allows for this practice to occur. However, this practice is also potentially a way to manage a constraint; that is, the separation of message construction and sending. Through examining the interaction through the lens of affordances, it is possible to see how the technological context allows for various actions to occur, but when we examine the actual instances of online interaction, we are able to see how the technology is used in practice, and how the affordances relate to the unfolding interaction.

\section{Openings of Facebook chats}

In this section, the opening sequences of Facebook chats are analysed, with a specific focus on the summons-answer and identification and recognition sequences, which have been identified in studies of spoken conversational openings (e.g., Schegloff, 1986, 1979). As with the previous section, the interactional practices will be analysed, before discussing how a focus on affordances can provide another level of understanding of the interactional context. 


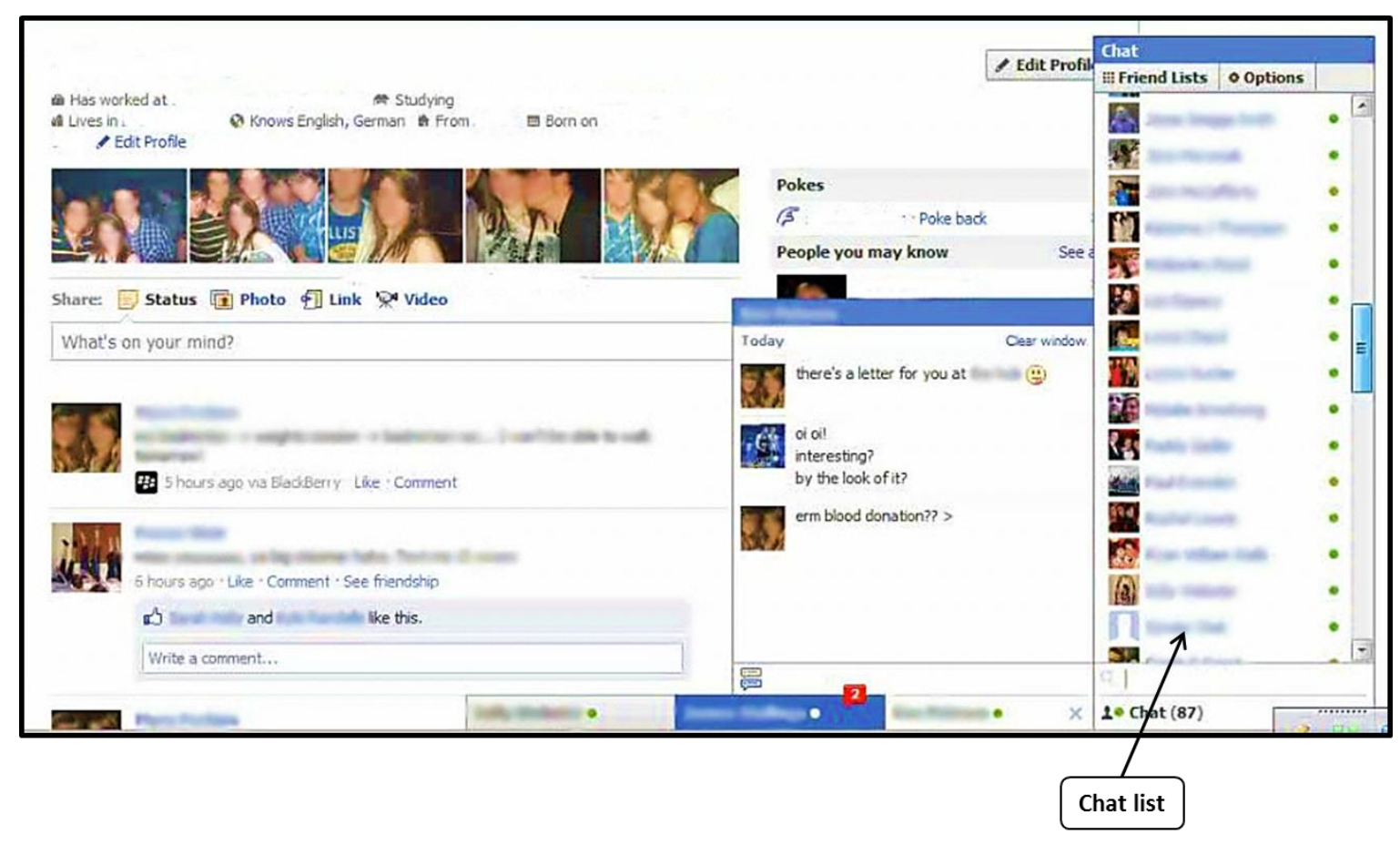

Figure 2 Facebook chat list

To start an instant messaging interaction in Facebook, the chat starter firstly has to check whether the intended recipient is online, which they can do through consulting the chat list (See Figure 2). The green dot next to the names of Facebook friends indicates that the other person is logged into chat. However, this visual indication that someone is online does not necessarily mean they are at their computer or willing to chat. 


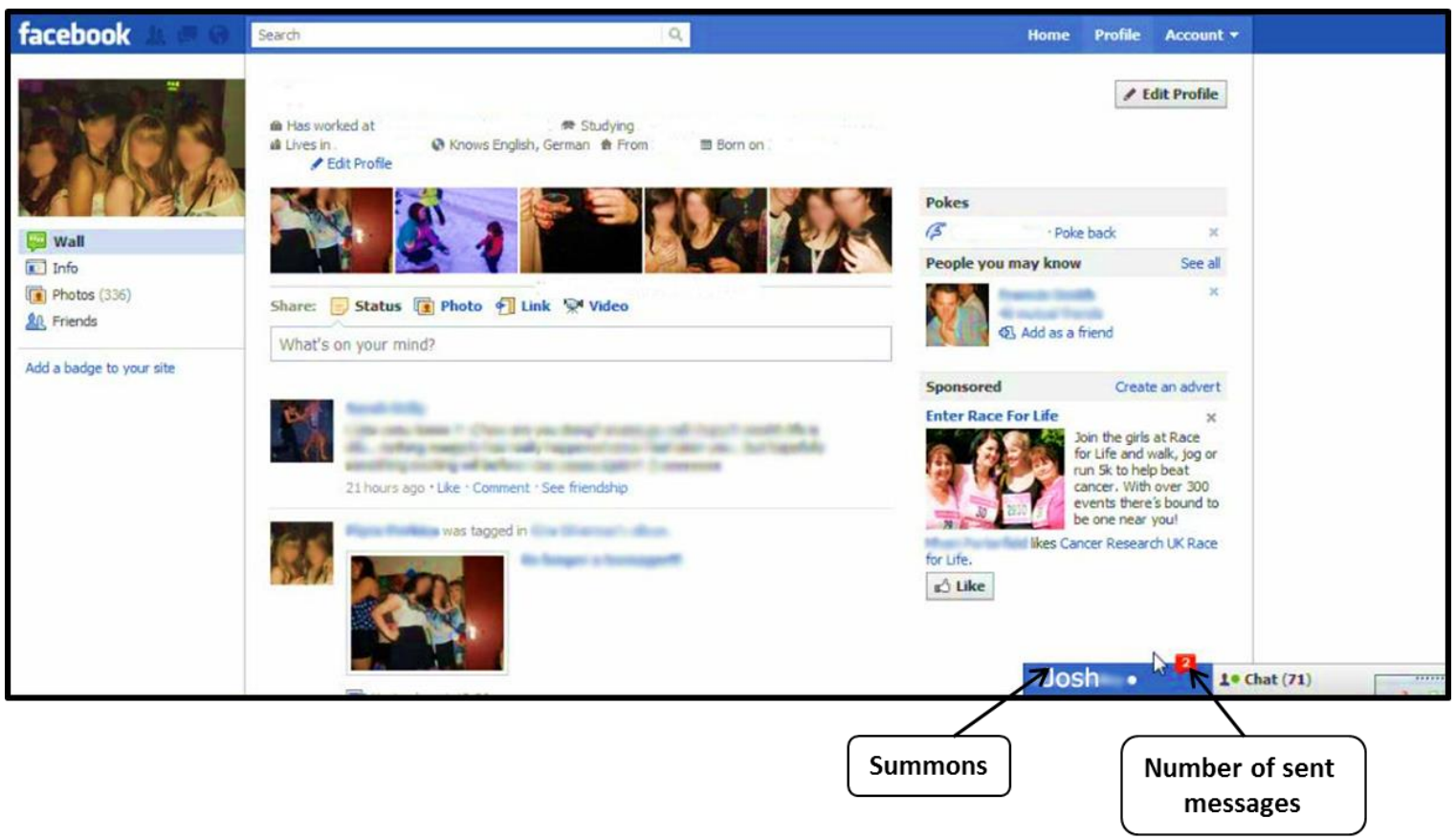

Figure 3: Facebook chat summons

The chat starter then clicks on the recipient's name to open a chat window with them and then has to type a message to the recipient, before pressing enter on their keyboard to send the message. The recipient receives an electronic notification; a chat window will 'pop up' on their screen, potentially accompanied by a short sound (depending on the recipient's computer set-up), as shown in Figure 3. This, I would argue, can be described a summons. In any interaction the 'summons' functions to "mobilize the attention... of [a] target as a way of launching an episode of interaction" (Schegloff, 2002, p.289). On the telephone, for example, the summons is the ringing of the telephone which indicates to the recipient that someone wishes to speak with them (Schegloff, 1968). In multi-party chat, it has been found that may be an automatic notification which informs already-present users of someone else joining the chatroom (Rintel, Mulholland \& Pittam, 2001). However, this does not mean that the joining party actually starts an interaction or wishes to chat. In this sense, it may not necessarily be categorised as a summons, as it does not launch an interaction. In Facebook chat, on the other hand, the technology requires that the summons is produced through constructing and 


\section{CONVERSATION ANALYSIS AND TECHNOLOGICAL AFFORDANCES}

sending a message, which will function as both the first turn of the interaction, but will also lead to the recipient receiving a notification. In Figure 3, the fact that Josh has summoned Isla is indicated by the appearance on her screen of the highlighted box with his name in it. The small bubble which appears above the box informs Isla how many messages have been sent as part of this summons (in this case Josh has sent two messages in quick succession). The summons, therefore, not only checks the availability of a recipient, but also always does another action. It is important to note, though, that this first action is issued before the sender has checked whether the recipient is definitely available. To understand the actions which this affordance makes possible, we can examine the design of the opening summonses.

In the analysis of the data, three different categories of summons were identified: greetings (Extract 5), personalised summonses (Extract 6) and topic-initiation (Extract 7).

\section{Extract 5: JM/IS25/B: 1}

1 Lucy: Heyy

Extract 6: JM/IS18/B: 1

1 Isla: boo

Extract 7: JM/KA13/B: 1

1 Katie: fish ate my feeeeet!

In Extract 5 a traditional greeting token is used, as we might expect in face-to-face interaction (Pillet-Shore, 2012). Greetings are also used in other online contexts, such as in text and voice chat rooms (Jenks \& Brandt, 2013), video messaging (Licoppe \& Morel, 2012) and in e-mails (Bou-Franch, 2011; Waldvogel, 2007). In using a greeting token, participants are 


\section{CONVERSATION ANALYSIS AND TECHNOLOGICAL AFFORDANCES}

treating this opening as no different to any other form of interaction, despite the fact that the greeting is issued prior to checking the availability of the recipient.

In Extract 6, we see a slightly different type of opening, where Isla mimics the type of playful interaction which could potentially be found in spoken interaction. It could also be argued that this is a playful orientation to the fact that a notification has appeared on the recipient's screen, with potentially an accompanying noise, which may have 'scared' the recipient. In Extract 7, Katie starts the interaction with a topic-initiation. Here, the summons checks the availability of the recipient, but also launches the first topic of the interaction. The fact that greetings are dispensed with entirely is not uncommon for online interaction (BouFranch 2011; Antaki, Ardévol, Núñez \& Vayreda, 2005). In this sense, the summonses in instant messaging interaction seem to be quite similar to those found in other text-based interaction and talk.

What this suggests is despite what might be seen as a technological constraint, that is, starting the interaction before checking if the recipient is available, seems to have little impact on how the interaction is actually started. However, the fact that the text remains onscreen does mean that the chat starter can start an interaction, including using a topicinitiation, which the recipient can view and respond to at any time. It is, perhaps, notable that in none of the openings in the data corpus do participants do an availability check (i.e. 'have you got time for a chat?' or 'are you there?'). Although the chat starter has some indication that the participant is, or has recently been, online, it is still possible that they may not be available at that particular moment. The lack of availability check implies that although the medium affords the possibility of instant interaction, participants do not necessarily treat a summons as requiring an instant response. In this sense, although this type of one-to-one instant messaging interaction might be called 'quasi-synchronous' (Garcia \& Jacobs, 1999), synchronicity is actually established by participants as part of the interaction. 


\section{Identification and recognition}

In landline telephone calls, it has been found that there is often an identification and recognition sequence (Schegloff, 1979); that is, where the participants ensure that they are speaking to whom they expect. Knowing that you are speaking to your intended recipient is important so that turns can be 'recipient-designed' (Sacks, Schegloff \& Jefferson, 1974); that is, the talk can be specifically designed for an intended recipient. In addition, as has been discussed elsewhere the presence of the identification and recognition sequence is an orientation to the lack of visual access between participants on the telephone (Schegloff, 1979).

In the Facebook chat corpus, the identification and recognition sequence rarely occurs. A deviant case, though, is presented - in which identification and recognition does occur - to demonstrate how the lack of this sequence in most chats orients to the affordances of Facebook chat. In this extract, Mary starts an interaction with Paul. However, it is actually Violet who is using Paul's Facebook account, which Mary does not realise until Violet identifies herself.

Extract 8: JM/VI/1:1-37

$\begin{array}{lcc}1 & \text { Mary: } & (16.0) \\ 2 & \text { hello } \\ 3 & \text { Paul: } & \text { hello } \\ 4 & \text { this } \text { is Violet stalking people } \\ 5 & \text { Paul: } & (4.0) \\ 6 & & \text { how are you? } \\ 7 & \text { Mary: } & (1.0) \\ 8 & & \end{array}$




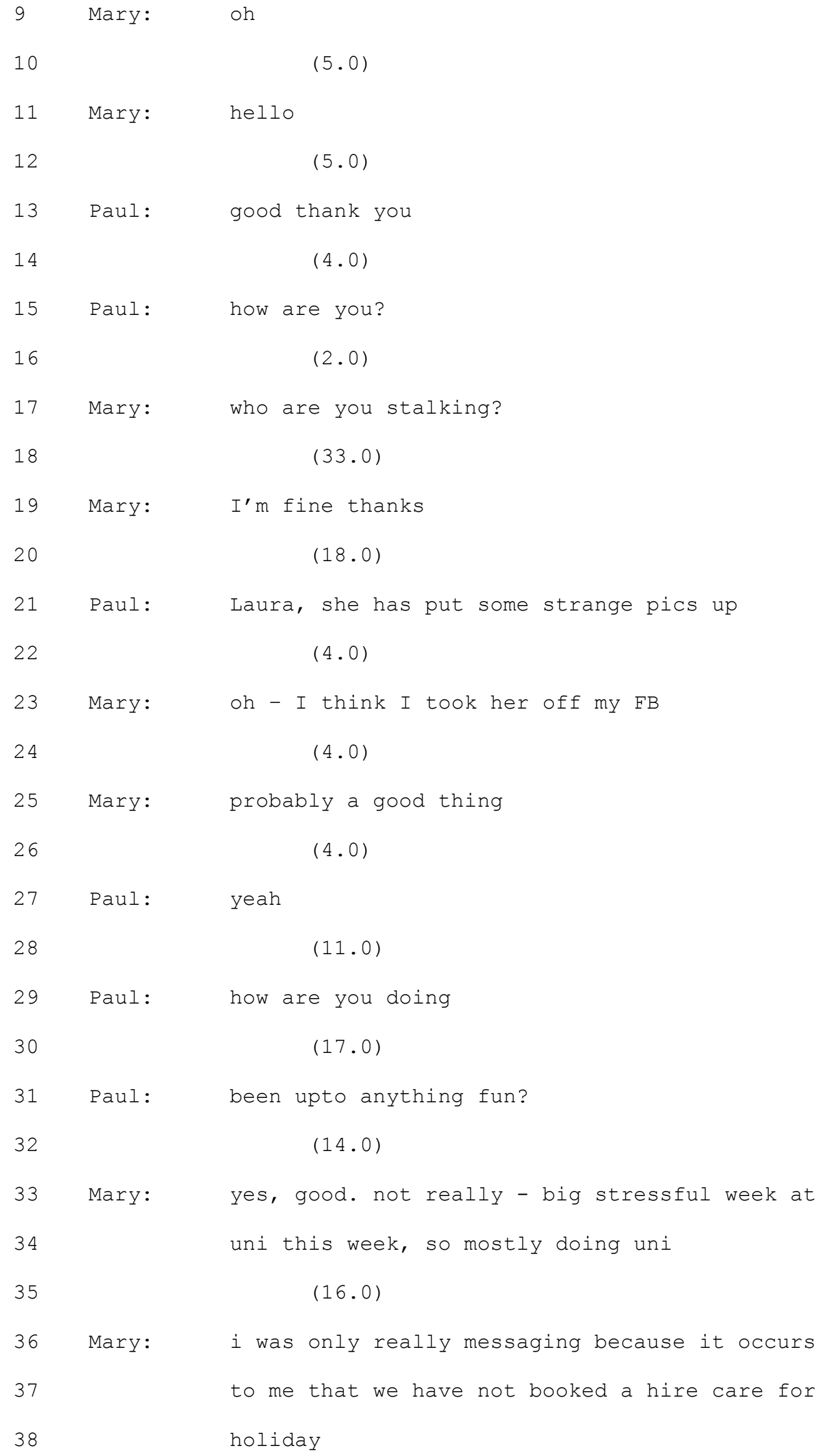




\section{CONVERSATION ANALYSIS AND TECHNOLOGICAL AFFORDANCES}

In line 1, Mary starts the interaction with a greeting token. Mary's greeting is responded to in line 3 with another greeting token. At this point Mary is not aware that it is Violet rather than Paul with whom she is chatting. It is interesting to note that Violet answers the summons before identifying herself, demonstrating the strength of the interactional imperative to provide the answer to a summons when issued (Schegloff, 1968). Violet identifies herself in line 5, and provides an account for why she is using Paul's Facebook page. Mary acknowledges Violet's identification in line 9 with a change-of-state token "oh" (Heritage, 1984). The position of this token suggests that Mary’s inquiry "how are you" at line 7 was constructed and posted before she noticed Violet's identification.

Interestingly, in her next turn Mary re-issues her greeting "hello", despite the fact that the pair had already exchanged greetings in lines 1-3. The reissuing of a greeting token suggests that Mary's first "hello" was designed for Paul, whereas the greeting in line 11 is designed for Violet. This example provides evidence that even a greeting token in Facebook chat is designed for a particular recipient.

This analysis has shown the interactional context of an identification and recognition sequence in Facebook chat; however, this extract also illuminates a number of affordances. Firstly, the visibility of the names of the participants in the chat window affords the possibility of knowing that the chat starter is interacting with their intended interlocutor. Usually, this affordance means that an identification and recognition sequence is interactionally unnecessary as "one should not tell one's coparticipants what one takes it they already know" (Goodwin, 1979, p.100). In addition, the availability of the identity of both interlocutors means that the summoner can recipient-design the opening for the intended recipient. In Extract 8, the name which is available to Mary is not the person she is speaking to, and so the identification and recognition sequence corrects a potential misidentification. This extract also provides evidence that there is another affordance at play here: the fact that 


\section{CONVERSATION ANALYSIS AND TECHNOLOGICAL AFFORDANCES}

a Facebook page belongs to an individual, and they will be the one who responds to the summons (see also Hutchby \& Barnett, 2005 on summons in mobile phone calls). In the extract above Violet orients to the fact that she is violating this norm as she provides an account for why she is on Paul's Facebook page. These are, then, the affordances which participants utilise when omitting an identification and recognition sequence, as there is a presumption that the person named will be the person who responds to the message.

This section has demonstrated how the opening sequences of Facebook chat can be systematically analysed using CA, and the technological affordances through which these practices are refracted can be identified using this method. The interactional practices suggest that, despite the potential technological constraints, the summonses used are very similar to those used in spoken interaction, thus implying that the technology actually has very little impact on the content of the interaction. However, the persistence of text on-screen affords for the first turn of the interaction to be issued, without knowing the recipient's availability. Therefore, we should potentially re-think notions around synchronicity being a fixed state, but rather it is a participants' concern. In addition, the omission of an identification and recognition sequence suggests that practices have arisen as a result of the names of participants being visible, as well as the presumption that the owner of the Facebook page is the person who will answer the chat.

\section{Discussion}

This paper has aimed to show how the systematic analysis of online interaction using CA can allow for the investigation of the interactional practices of online platforms. In addition, examining technological affordances can allow for an analysis which takes account of the technological context. The analysis of the data showed that, as previous studies have discussed (Garcia \& Jacobs, 1999; Berglund, 2009), the inability to mutually co-ordinate 


\section{CONVERSATION ANALYSIS AND TECHNOLOGICAL AFFORDANCES}

turns impacts upon turn adjacency. However, it was also shown that participants often created further disrupted turn adjacency irrespective of the separation of message construction and sending, through the production of multiple turns and responding to them in a list form (Hutchby \& Tanna, 2008; Nilsen \& Mäkitalo, 2010). The analysis of the opening sequences of Facebook chat demonstrated implicit orientations to: the way in which the medium enables summonses to be produced; the persistence of text online; the availability of participant's names; and individual ownership of Facebook pages.

There are various implications of analysing online interaction in this way. Firstly, in the literature on computer-mediated communication there is often some endeavour to categorise technology. For example, Herring (2007) categorises technologies according features such as synchronicity, granularity, number of channels and so on. Yet, from analysing empirical data using CA we can see that these aspects are participants' concerns. For example, although Facebook chat can be defined as quasi-synchronous (Garcia \& Jacobs, 1999), that synchronicity is not a fixed feature but rather is something that participants negotiate through the course of the interaction. A second implication is that for those using digital CA, there is a danger that in wanting to analyse the role of technology, the analysis of the interaction itself is not as detailed as it could be. In addition, as previously noted, it is important to avoid presuming that CA findings from spoken interaction can be applied to online interaction (Greiffenhagen \& Watson, 2005; Giles et al., 2015). By using the two-step process described in this article, the interaction can be analysed and the technological context be taken account of as part of that analysis. Although it may seem a somewhat artificial distinction, analysing the interaction itself first and then examining how the affordances are oriented to in the data allows for an in-depth analysis which avoids presuming that the technology plays a particular role or that findings from spoken interaction will be relevant. A final implication, which has been implicit in this paper, is that the use of screen-capture data can allow for the analysis of 


\section{CONVERSATION ANALYSIS AND TECHNOLOGICAL AFFORDANCES}

moment-by-moment production of online interaction, as it occurred for the participant (Author \&\{anonymised\}, 2013; Reeves \& Brown, 2016). While timed log files are, clearly, useful for being able to analyse the interaction itself, the screen-capture data can provide additional insights into how the interaction actually unfolds. For example, when analysing the affordances around disrupted turn adjacency it is particularly instructive to be able to see when the writing icon appears on participants' screens. Similarly, in the deviant case presented in the openings section, it would have been useful to have screen-capture data so that further analysis of which turns were recipient-designed for Paul and which for Violet could be conducted.

This study focused on text-based interaction as, at the time of data collection, Facebook chat only afforded that possibility. Clearly, many online platforms now afford the possibility of multi-modality, allowing for pictures and videos to be included (Rainie, Brenner \& Purcell, 2012). It is important to note, though, that even though these possibilities are afforded by the medium, it does not necessarily mean that more multi-modal interaction occurs. Instead, the ways in which participants make use of this multi-modality should be a concern of analysts, not presumed a priori to impact the interaction. The development of more multi-modal interaction does, though, pose a challenge for 'digital CA' in terms of how to embed the analysis of both textual and visual aspects into the analysis of the interaction (although see Tolins \& Samerit, 2016 for a recent example).

The utility of analysing the affordances of an interaction provides analysts with some handle on the context of that interaction. In spoken CA the setting in which an interaction takes place, such as a doctor's surgery, law court, helpline, is not understood as being relevant unless the participants orient to it (Heritage, 2004). As has been shown here, instead of presuming that any particular feature of the technology necessarily impacts the interaction, the notion of affordances can be used to better understand the relationship between the 


\section{CONVERSATION ANALYSIS AND TECHNOLOGICAL AFFORDANCES}

technology and those using it for communication. The upshot of doing analysis in the way presented in this article is that it allows for a systematic, rigorous method for analysing data across multiple platforms. In this sense, digital CA could develop into a method which is akin to 'institutional' CA (Heritage, 2004), in that it could provide comparisons of the organization of different communicative, or technological, contexts. In doing so, CA can provide a more developed understanding of the ways in which technology is impacting upon our communicative practices

\section{Acknowledgements}

I would like to thank two anonymous reviewers for their comments and suggestion. This work was supported by the Economic and Social Research Council [Grant number: ES/[903321/1].

\section{References}

Antaki, C., Ardévol, E., Núñez, F., \& Vayreda, A. (2005). "For she who knows who she is": Managing accountability in online forum messages. Journal of Computer-Mediated Communication, 11(1). Retrieved from http://jcmc.indiana.edu/vol11/issue1/antaki.html

Benwell, B., \& Stokoe, E. (2006). Discourse and identity. Edinburgh: Edinburgh University Press.

Berglund, T. Ö. (2009). Disrupted turn adjacency and coherence maintenance in instant messaging conversations.Language@Internet, 6, Article 2. Retrieved from www.languageatinternet.de/articles/2009/2106/Berglund.pdf/

Bou-Franch, P. (2011). Openings and closings in Spanish email conversations. Journal of Pragmatics, 43, 1772-1785. Doi:10/1016/j.pragma.2010.11.002 


\section{CONVERSATION ANALYSIS AND TECHNOLOGICAL AFFORDANCES}

Garcia, A. C., \& Jacobs, J. B. (1999). The eyes of the beholder: Understanding the turntaking system in quasi-synchronous computer-mediated communication. Research on Language and Social Interaction, 32(4), 337-367.

Gibson, J.J. (1979). The ecological approach to perception. London: Houghton Mifflin.

Giles, D., Stommel, W., Paulus, T., Lester, J., \& Reed, D. (2015). Microanalysis of online data: The methodological development of "digital CA". Discourse, Context \& Media, 7, 45-51.

Goodwin, C. (1979). The interactive construction of a sentence in natural conversation. In G.

Psathas (Ed.), Everyday language: Studies in ethnomethodology (pp. 97-121). New

York: Irvington Publishers.

Greenfield, P. M., \& Subrahmanyam, K. (2003). Online discourse in a teen chatroom: New codes and new modes of coherence in a visual medium. Journal of Applied Developmental Psychology, 24(6), 713-738.

Greiffenhagen, C., \& Watson, R. (2005). “Teoria" e “método" na CMC: Identidade, género e tomada-deturno: Uma abordagem etnometodológica e analítico conversacional. In A. Braga (Ed.), CMC, identidades e género: Teoria e método ["Theory" and "Method" in CMC: Identity, gender, and turn-taking: An ethnomethodological and conversation analytic approach] (pp. 89-114). Covilhã: Universidade da Beira Interior.

Heritage, J. (1984). A change-of-state token and aspects of its sequential placement. In J. M. Atkinson, \& J. Heritage (Eds.), Structures of social action: Studies in conversation analysis (pp. 299-345). Cambridge: Cambridge University Press.

Heritage, J. (2004). Conversation analysis and institutional talk: Analyzing data. In D.

Silverman (Ed.), Qualitative research: Theory, method and practice (pp. 222-245). London: Sage.

Herring, S. C. (1999). Interactional coherence in CMC. Journal of Computer-Mediated 


\section{CONVERSATION ANALYSIS AND TECHNOLOGICAL AFFORDANCES}

Communication, 4(4). Retrieved from

http://www.ascusc.org/jcmc/vol4/issue4/herring.html

Herring, S. C. (2007). A faceted classification scheme for computer-mediated discourse.

Language@Internet, 4, Article 1. Retrieved from

http://www.languageatinternet.org/articles/2007/761

Hutchby, I. (2001). Technologies, texts and affordances. Sociology, 35, 441-456.

Hutchby, I., \& Barnett, S. (2005). Aspects of the sequential organization of mobile phone conversation. Discourse Studies, 7(2), 147-171.

Hutchby, I., \& Tanna, V. (2008). Aspects of sequential organization in text message exchange. Discourse \& Communication, 2(2), 143-164.

Jenks, C. J., \& Brandt, A. (2013). Managing mutual orientation in the absence of physical copresence: Multiparty voice-based chat room interaction. Discourse Processes, 50(4), $227-248$.

Licoppe, C., \& Morel, J. (2012). Video-in-interaction: "Talking heads" and the multimodal organization of mobile and Skype video calls. Research on Language and Social Interaction, 45(4), 399-429.

Markman, K. M. (2009). "So what shall we talk about": Openings and closings in chat-based virtual meetings. Journal of Business Communication, 46(1), 150-170.

Nilsen, M., \& Mäkitalo, Å. (2010). Towards a conversational culture? How participants establish strategies for co-ordinating chat postings in the context of in-service training. Discourse Studies, 12(1), 90-105.

Norman, D.A. (1988). The psychology of everyday things. New York: Basic Books

Paulus, T. M., \& Lester, J. N. (2013). Making learning ordinary: Ways undergraduates display learning in a CMC task. Text \& Talk, 33(1), 53-70. 


\section{CONVERSATION ANALYSIS AND TECHNOLOGICAL AFFORDANCES}

Paulus, T., Warren, A., \& Lester, J. N. (2016). Applying conversation analysis methods to online talk: A literature review. Discourse, Context \& Media. doi:10.1016/j.dcm.2016.04.001

Pillet-Shore, D. (2012). Greeting: Displaying stance through prosodic recipient design. Research on Language and Social Interaction, 45(4), 375-398.

Raine, L. Brenner, J. \& Purcell, K. (2012). Photos and videos as social currency online. Pew Internet Research Center. Available: http://www.pewinternet.org/files/oldmedia/Files/Reports/2012/PIP_OnlineLifeinPictures_PDF.pdf

Reeves, S., \& Brown, B. (2016). Embeddedness and sequentiality in social media. In Proceedings of the 19th ACM Conference on Computer-Supported Cooperative Work \& Social Computing (CSCW'16). ACM, New York, NY, USA, 1052-1064.

Rintel, S. (2013, January). Tech-tied or tongue-tied? Technological versus social trouble in relational video calling. In System Sciences (HICSS), 2013 46th Hawaii International Conference on Systems Sciences (pp. 3343-3352). IEEE.

Rintel, E. S., Mulholland, J., \& Pittam, J. (2001). First things first: Internet Relay Chat openings. Journal of Computer-Mediated Communication, 6(3). Retrieved from http://onlinelibrary.wiley.com/doi/10.1111/j.1083-6101.2001.tb00125.x/full

Sacks, H. (1987). On the preferences for agreement and contiguity in sequences in conversation. In G. Button, \& J. R. E. Lee (Eds.), Talk and social organisation (pp. 5469). Clevedon: Multilingual Matters.

Sacks, H., Schegloff, E. A., \& Jefferson, G. (1974). A simplest systematics for the organization of turn-taking in conversation. Language, 50(4), 696-735.

Schegloff, E. A. (1968). Sequencing in conversational openings. American Anthropologist, $70,1075-1095$.

Schegloff, E. A. (1979). Identification and recognition in telephone conversation openings. In 


\section{CONVERSATION ANALYSIS AND TECHNOLOGICAL AFFORDANCES}

G. Psathas (Ed.), Everyday language: Studies in ethnomethodology (pp. 23-78). New York: Irvington Publishers.

Schegloff, E. A. (1986). The routine as achievement. Human Studies, 9, 111-151.

Schegloff, E. A. (2002). Beginnings in the telephone. In J. E. Katz, \& M. A. Aakhus (Eds.), Perpetual contact: Mobile communication, private talk, public performance (pp. 284300). Cambridge: Cambridge University Press.

Schegloff, E.A. (1991). Reflections on talk and social structure. In D. Boden and D.H. Zimmerman (eds) Talk and social structure. (pp.44-70). Berkeley: University of California.

Schegloff, E. A., \& Sacks, H. (1973). Opening up closings. Semiotica, 8(4), 289-327.

Schönfeldt, J., \& Golato, A. (2003). Repair in chats: A conversation analytic approach. Research on Language and Social Interaction, 36(3), 241-284.

Sidnell, J. (2011). Conversation analysis: An introduction. Singapore: John Wiley \& Sons.

Stommel, W., \& Koole, T. (2010). The online support group as a community: A microanalysis of the interaction with a new member. Discourse Studies, 12(3), 357-378.

Stommel, W., \& van der Houwen, F. (2013). Formulations in "trouble" chat sessions. Language@Internet, 10, Article 3. Retrieved from http://www.languageatinternet.org/articles/2013/stommel

Tolins, J., \& Samerit, P. (2016). GIFs as embodied enactments in text-mediated conversation. Research on Language and Social Interaction, 49(2), 75-91.

Tudini, V. (2015). Extending prior posts in dyadic online text chat. Discourse Processes, $52(8), 642-669$.

Turk, M. (2004). Using and in conversational interaction. Research on Language and Social Interaction, 37(2), 219-250.

Waldvogel, J. (2007). Greetings and closings in work place email. Journal of Computer- 
CONVERSATION ANALYSIS AND TECHNOLOGICAL AFFORDANCES

Mediated Communication, 12(2), 456-477.

\section{Appendix: Full list of transcription symbols}

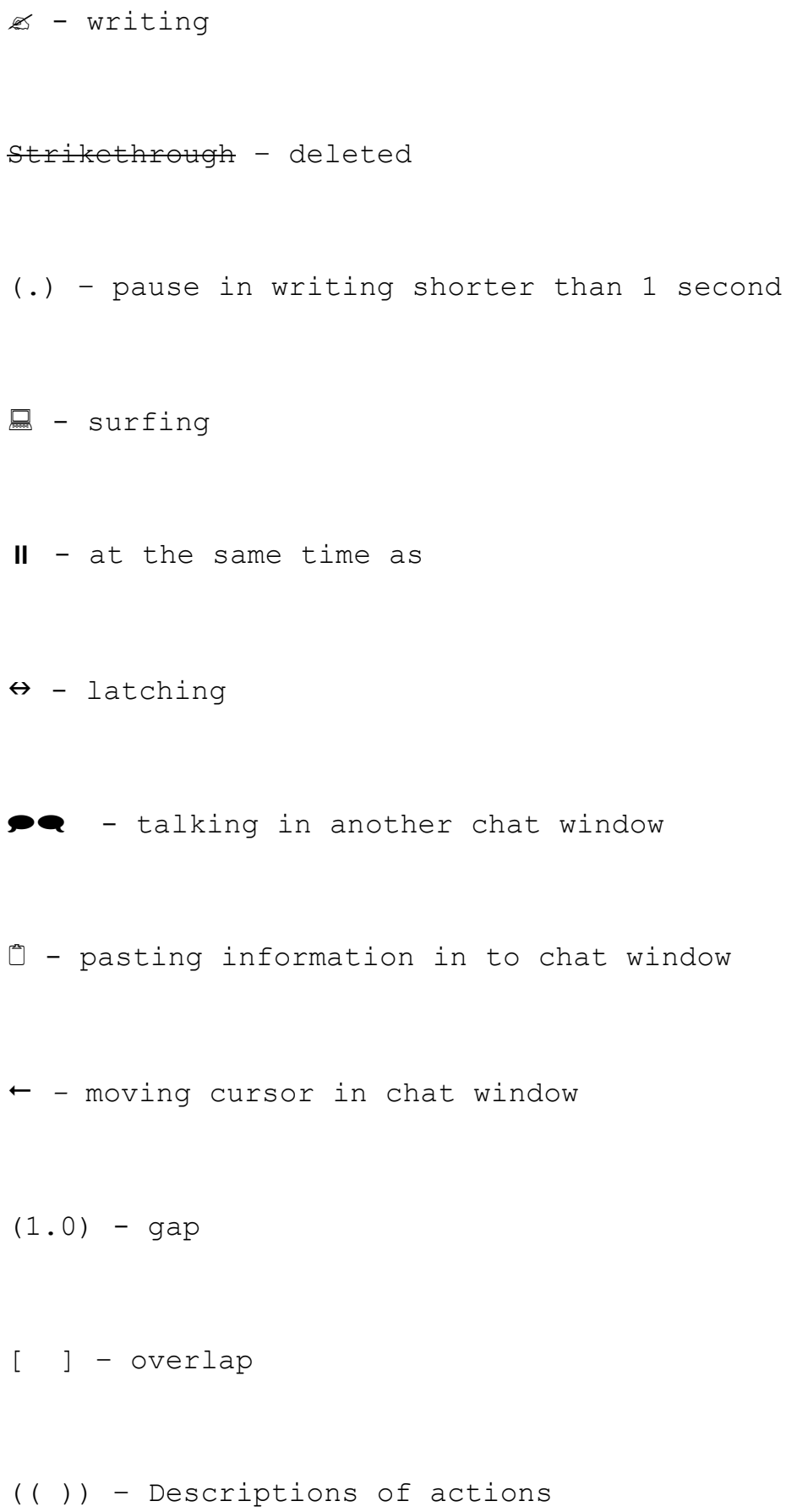

